\title{
Associations among Morphological and Phonological Characters Representing Apricot Germplasm in Central Mexico
}

\author{
S. Perez-Gonzales \\ Instituto National de Investigaciones Forestales y Agropecuanas-Campo Experimental Norte de \\ Guanajuato, Prolongación Zaragoza 408 Jardines de la Hacienda, Queretaro, Qro. 76180, Mexico
}

Additional index words. Prunus armeniaca, growth habit, fruiting spurs, leaf area, fruit size, descriptor, fruit breeding

\begin{abstract}
Twenty variables were recorded on 15 apricot (Prunus armeniaca L.) genotypes differing in growth habit and blossom time to detect possible associations among morphological and phonological traits. The widest range of variability observed among phenotypes was for fruit size and factors associated with adaptation to local conditions, such as blossom season and yield potential as expressed by number of buds, flowers, and fruits per length of fruiting spurs. The most important morphological traits correlated with fruit weight were tree growth habit, apical and basal diameter of fruiting spurs, and bud and leaf size. Multivariate analysis allowed tree and variable grouping, which might encompass the basic criteria for apricot breeding programs in central México.
\end{abstract}

More than $80 \%$ of the world apricot production is restricted to Mediterranean climates (Caccamisi et al., 1987; Westwood, 1975). Apricots could be cultivated commercially in other areas of the world to satisfy local demand. In the semiarid regions of México, apricots have been grown for more than two centuries and show a wide range of adaptation, but produce relatively small fruit.

With the exception of 'Canine' and 'San Castrese', which show a wider range of adaptation (C. Fideghelli, personal communication), apricot cultivars are highly specific in their ecological requirements (Bailey and Hough, 1975) and cannot be successfully cultivated away from their place of origin. Local breeding outside traditional growing regions should be encouraged to widen the distribution and cultivation of apricots (Bailey and Hough, 1975).

The early stages of any breeding program require germplasm collection and characterization. However, the information available on apricot descriptors includes mainly varieties from the European group (Couranjou, 1977; Sansavini et al., 1987). They are based on a wide range of characteristics, such as tree vigor and growth habit, leaf size and shape, productivity (Brooks and Olmo, 1972; Couranjou, 1977; Fideghelli and Monastra, 1977), disease resistance (Crossa-Raynaud, 1969; Guerriero and Watkins, 1984), fruit quality (Brooks and Olmo, 1972; Couranjou, 1977; Fideghelli and Monastra, 1977; Guerriero and Watkins, 1984; Monastra et al., 1984), and isozyrne differences (Byrne and Littleton, 1989).

More than three decades ago, Lapins et al. (1957) detected a high parent-offspring correlation for fruit size and flesh firmness, two of the most important traits related to fruit quality. However, with the exceptions of the report by Cociu (cited by Bailey and Hough, 1975) and the personal communication by C. Fideghelli and G. Della Strada (1991), very little information is available about simple associations between morphological traits and fruit quality in apricots.

The use of multivariate analysis has been used successfully in annual species to relate morphological and phonological traits with geographic and genetic origin in beans (Martin and Adams,

Received for publication 24 Apr. 1991. Accepted for publication 27 Dec. 1991 I acknowledge Carlos Mejia and Jesus Sanchez for the statistical support provided for this work. The cost of publishing this paper was defrayed in part by the payment of page charges. Under postal regulations, this paper therefore must be hereby marked advertisement solely to indicate this fact. 1987a, 1987b) and in perennial fruit species, such as sour cherries (Prunus cerasus L.) (Hilling and Iezzoni, 1988).

The main objective of this study was to describe the variability of several morphological and horticultural traits in apricot germplasm growing in central Mexico to detect possible associations among morphological traits and fruit size and variables that could be related to adaptation to local conditions.

\section{Materials and Methods}

Seed samples from orchards and village markets in the main apricot-growing regions in central Mexico were collected in 1984. In Spring 1985, resulting seedlings were planted at a semiarid location in northern Guanajuato, at a 2000-m elevation with 400 to 550 chilling hours. Seedling trees were grown using standard cultural practices.

The trees were classified according to growth habit and budbreak season during 1986-89. Fourteen seedling trees representing a wide range in growth habits and 'Canine' were evaluated for 20 traits in 1989 and 1990 . The growth habit $(\mathrm{GH})$ was evaluated visually using a scale, where $1=$ bushy with a high degree of branching to $5=$ erect and compact. The overall productivity $(\mathrm{P})$ of the tree was rated, where $1=$ very low to $5=$ very high. Budbreak (BB) and harvest season (HS) ratings ranged from $1=$ very early to $5=$ very late. During bloom, the following measurements or counts were taken on 20 spurs per tree chosen randomly: the length of the spur (Ifs); basal and apical diameter of the spur ( $\mathrm{Bd}$ and $\mathrm{Ad}$, respectively); the size of flower buds (bd); the number of flowers per spur (fl); and the number of fruits per spur 8 weeks after full bloom. Ten fruiting branches were chosen randomly around the canopy at a height of 1.6 to $2.2 \mathrm{~m}$, and the following measurements or counts were taken: branch diameter $5 \mathrm{~cm}$ above its base [it then

Abbreviations: Ad, apical diameter of spur; BB, budbreak season; bcsa, branch cross-sectional area; Bd, basal diameter of spur; bd, diameter of flower bud; $\mathrm{Bd}$ : Ad, basal diameter : apical diameter; fbn, number of flower buds per spur; fbn : Ifs, unopened flower buds per length of spur; fl, number of flowers per spur; fl : fbrr, flower : unopened flower buds; ff : Ifs, flowers per length of spur; fn, number of fruits per branch; fr : ifs, fruit per length of spur; fw, individual fruit weight; FW, weight of fruit per branch; FW : bcsa, yield efficiency; fw : sw, fruit : seed; GH, growth habit; HS, harvest season; 1, number of leaves per branch; la, individual leaf area; LA, total leaf area per branch; LA : FW, total leaf area : fruit weight; 1 : fn, number of leaves : number of fruit; Ifs, length of spur; $P$, productivity; sw, individual seed weight. 
was converted to branch cross-sectional area (bcsa)]; number of leaves (1); and number (fn) and weight of fruits (FW). The leaf area (la) of 20 individual leaves per tree was measured using an electronic meter (Delta T-area measurement system; Decagon Devices, Pullman, Wash.). The individual fruit (fw) and seed weights (Sw) of 20 fruits per tree were determined at harvest.

From these measurements or counts, nine more variables were calculated. These were: the ratio of $\mathrm{Bd}$ : $\mathrm{Ad}$; the number of buds, flowers, and fruits per length of spur (fbn/ifs, fl/lfs, and fr/lfs $\times 100$, respectively); the ratio of the number of flowers to the total number of buds per spur at blossom (fl/fbn); the ratio of 1: fn; the ratio of total leaf area (LA, average individual leaf area $x$ number of leaves per branch) to FW (LA : FW); yield efficiency as FW to bcsa (FTV : bcsa); and the ratio of fW : SW.

Using mean values, associations among variables, as well as seedling grouping, were performed using Principal Component Analysis (Crisci and Lopez, 1983; Iezzoni and Pritts, 1991).

\section{Results and Discussion}

There was a wide range of variability among genotypes for most traits studied (Table 1), especially for those factors associated with yield efficiency, such as leaf area in relation to fruit produced ( 1 : fn, LA : FW, and FW : bcsa). This variation might be the result of different periods of natural and artificial selection under local conditions, as has been reported for other species (Montez, 1989). In addition to these variables, there was a group of traits that were slightly less variable but also associated with yield: fl : Ifs, fr : lfs, fl : fbn, fw, sw, and fw : sw. Some cultivar differences associated with yield components have also been reported for perennial species such as pears (Pyrus communis L.) (Kappel, 1990), blueberries (Vaccinium corymbosum L.) (Siefker and Hancock, 1986), and sour cherries (Chang et al., 1987).

With a similar degree of variability, there were three morphological (la, Ad, and Bd : Ad) and two phonological traits (BB and HS) that, with the other variables mentioned, could constitute the basis to define apricot tree groupings for selection purposes.

Finally, there was another set of factors that exhibited less variability among trees and included Ifs, bd, and fbn : ifs.

During the early stages of any breeding program, the main objective should be adaptability to local conditions (Bailey and
Hough, 1975; Brauer, 1973). This is a highly complex factor, and in this study it was associated mainly with BB, fl : fbn, LA : FW, FW : bcsa, and fr : Ifs.

Early blooming genotypes, with early BB $(<2)$, are more susceptible to frosts, while those that bloom very late $(\mathrm{BB}=$ 5) are shy bearers under local conditions due to insufficient chilling accumulation. When winter chilling accumulation is enough to satisfy the requirements of a given phenotype, a high proportion of buds will be breaking (high $\mathrm{fl}: \mathrm{fbn}$ ), as has been reported for peach [Prunus persica (L.) Batsch] (Scalabrelli and Couvillon, 1986). In our study, fl: fbn was positively correlated with fl : lfs $(r-=0.91)$, fr : Ifs $(r=0.68), \mathrm{FW}:$ bcsa $(r=$ $0.66)$, and $\mathrm{P}(r=0.66)$ (Table 2$)$. However, it was negatively associated with some other important traits, such as GH $(r=$ $-0.67)$, Bd $(r=-0.87)$, Ad $(r=-0.82)$, la $(r=-0.83)$, and fw $(r=-0.86)$.

Once abroad basis for adaptation to local conditions has been established, some morphological factors related with tree structure become important to increase the efficiency of orchard management practices (Fideghelli et al., 1991; Scorza et al., 1986). In this study, I observed that a willowy growth habit, with values of $\mathrm{GD}<2$, demands more hand labor for pruning, spraying, and harvesting than the erect and more compact growth forms $(\mathrm{GH}=4$ and 5). Weak fruiting spurs with a narrow, pointed apex and values for $\mathrm{Bd}$ : $\mathrm{Ad}>3$ (Table 1) make pruning and harvesting operations more difficult and are associated with smaller fruit ( $r=0.76$ with fw).

More than 70 correlations among some of the 20 variables included on this study where higher than 0.6 and mainly involve $\mathrm{GH}$, la, bd, Bd, Ad, and fw (Table 2). These associations could provide an efficient tool for selection purposes. For example, erect, compact growth habit $(\mathrm{GH}=4$ and 5), which is relatively easy to identify in the field, is strongly associated with other morphological traits, such as thicker fruiting spurs $(r=0.88$ and $r=0.82$ for $\mathrm{Bd}$ and $\mathrm{Ad}$, respectively), larger leaves ( $r=$ $0.82, \mathrm{la})$, fruits $(r=0.79$, fw), and seeds $(r=0.81$, sw), and with more leaves per fruit $(r=0.61,1: \mathrm{fn})$. However, this trait is negatively correlated with some other important variables, such as the proportion of buds breaking and turning into flowers $(r=0.67, \mathrm{fl}$ : fbn), fruits per meter of fruiting spur $(r$ $=0.64$, fr $:$ Ifs $)$, and $\mathrm{P}(r=-0.46)$. This negative correlation means that, at least for this study, the more desirable tree structure for orchard management is less productive under this environment, possible due to a higher chilling requirement, as

Table 1." Description of apricot germplasm growing in central Mexico.

\begin{tabular}{|c|c|c|c|c|c|c|c|c|c|c|c|c|c|c|c|c|c|c|c|c|}
\hline Accession & $\mathrm{GH}$ & & $\begin{array}{c}\mathrm{Bd} \\
(\mathrm{mm})\end{array}$ & $\begin{array}{c}\mathrm{Ad} \\
(\mathrm{mm})\end{array}$ & $\mathrm{Bd}: \mathrm{Ad}$ & $\begin{array}{l}\text { lfs } \\
(\mathrm{cm})\end{array}$ & $\begin{array}{c}\mathrm{bd} \\
(\mathrm{mm})\end{array}$ & $\begin{array}{c}\text { fbn:Ifs } \\
\text { (fbn:m) }\end{array}$ & $\begin{array}{l}\text { fl:lfs } \\
\text { (fl:m) }\end{array}$ & $\mathrm{fl}: \mathrm{fbn}$ & $\begin{array}{c}\text { fr:Ifs } \\
\text { (fr:m) }\end{array}$ & $\begin{array}{c}\text { la } \\
\left(\mathrm{cm}^{2}\right)\end{array}$ & 1:fn & $\begin{array}{c}\text { LA:FW } \\
\left(\mathrm{cm}^{2} \cdot \mathrm{g}^{-1}\right)\end{array}$ & $\begin{array}{l}F W: b c s a \\
\left(\mathrm{~g} \cdot \mathrm{cm}^{-2}\right)\end{array}$ & $\begin{array}{l}\text { fw } \\
(\mathrm{g})\end{array}$ & $\begin{array}{l}\text { sw } \\
\text { (g) }\end{array}$ & fw:sw & $\mathrm{HS}$ & $\mathrm{P}$ \\
\hline I1-18 & 4 & 2 & 3.7 & 2.1 & 1.8 & 10.1 & 2.1 & 147 & 31.0 & 0.21 & 30.7 & 46.0 & 17.8 & 25.1 & 374 & 29.4 & 1.9 & 15.7 & 2 & ? \\
\hline $\mathrm{I} 10-2$ & 3 & 2 & 2.9 & 0.9 & 3.0 & 13.9 & 1.8 & 96 & 43.3 & 0.45 & 40.5 & 20.3 & 8.5 & 12.5 & 285 & 13.4 & 1.1 & 12.4 & 3 & 4 \\
\hline II $2-8$ & 3 & 2 & 2.8 & 1.0 & 2.7 & 10.1 & 1.6 & 74 & 35.6 & 0.48 & 31.2 & 24.2 & 35.0 & 40.7 & 180 & 21.3 & 1.0 & 21.1 & 1 & 2 \\
\hline II3-11 & 4 & 5 & 3.6 & 2.6 & 2.3 & 13.3 & 1.9 & 169 & 32.0 & 0.21 & 15.0 & 43.3 & 35.0 & 14.6 & 157 & 18.2 & 1.8 & 10.2 & 1 & 2 \\
\hline II $4-1$ & 2 & 3 & 2.7 & 1.0 & 2.7 & 12.6 & 1.5 & 139 & 50.0 & 0.36 & 35.4 & 15.6 & 15.5 & 13.9 & 264 & 12.3 & 1.1 & 11.4 & 4 & 3 \\
\hline II4-4 & 3 & 2 & 2.3 & 0.9 & 2.4 & 10.3 & 1.7 & 146 & 68.0 & 0.47 & 65.8 & 20.2 & 7.4 & 4.1 & 462 & 12.2 & 1.4 & 9.2 & 2 & 5 \\
\hline II $4-5$ & 3 & 2 & 2.5 & 0.7 & 3.2 & 12.7 & 1.8 & 128 & 48.0 & 0.37 & 31.7 & 18.2 & 7.2 & 9.7 & 386 & 13.5 & 1.4 & 9.9 & 2 & 5 \\
\hline II $7-3$ & 1 & 2 & 2.1 & 0.6 & 3.7 & 9.5 & 1.5 & 161 & 59.6 & 0.37 & 43.2 & 14.3 & 6.0 & 14.9 & 230 & 5.8 & 0.5 & 12.5 & 4 & 4 \\
\hline II8-3 & 1 & 2 & 2.1 & 0.5 & 3.9 & 12.9 & 1.4 & 136 & 61.0 & 0.45 & 37.6 & 9.2 & 9.9 & 15.0 & 268 & 5.5 & 0.6 & 9.4 & 4 & 4 \\
\hline II8-9 & 2 & 3 & 2.2 & 0.7 & 3.0 & 12.8 & 1.7 & 108 & 47.0 & 0.43 & 45.4 & 10.5 & 13.1 & 15.1 & 153 & 15.3 & 1.1 & 13.4 & 4 & 4 \\
\hline III1-1 & 1 & 2 & 2.3 & 0.8 & 3.0 & 12.7 & 1.6 & 165 & 61.0 & 0.37 & 74.4 & 20.1 & 12.0 & 24.6 & 408 & 14.3 & 1.0 & 14.3 & 4 & 3 \\
\hline III1-5 & 5 & 5 & 4.8 & 2.2 & 2.1 & 10.2 & 2.6 & 137 & 15.0 & 0.11 & 14.4 & 42.1 & 32.0 & 31.6 & 195 & 42.5 & 2.1 & 20.3 & 2 & 1 \\
\hline III $2-2$ & 4 & 1 & 3.6 & 1.5 & 2.4 & 11.9 & 2.0 & 133 & 44.3 & 0.33 & 23.2 & 24.9 & 34.5 & 53.0 & 236 & 26.8 & 1.1 & 23.9 & 1 & 3 \\
\hline III6-6 & 4 & 3 & 3.0 & 1.0 & 3.0 & 17.1 & 1.9 & 103 & 37.0 & 0.36 & 31.3 & 31.4 & 52.9 & 42.2 & 175 & 28.2 & 1.7 & 16.9 & 3 & 4 \\
\hline Canino & 3 & 3 & 3.6 & 1.8 & 2.0 & 12.5 & 1.9 & 126 & 25.0 & 0.20 & 21.2 & 35.6 & 45.2 & 58.8 & 151 & 37.6 & 2.2 & 17.2 & 2 & 4 \\
\hline
\end{tabular}


Table 2. Correlation matrix among variables studied to describe apricot germplasm in central Mexico.

\begin{tabular}{|c|c|c|c|c|c|c|c|c|c|c|c|c|c|c|c|c|c|c|c|}
\hline & GH & BB & $\mathrm{Bd}$ & $\begin{array}{c}\text { Ad } \\
(\mathrm{mm})\end{array}$ & $\begin{array}{l}\text { Bd:Ad } \\
(\mathrm{mm})\end{array}$ & Ifs & $\begin{array}{l}\mathrm{bd} \\
(\mathrm{cm})\end{array}$ & $\begin{array}{c}\text { fbn:lfs } \\
\text { (mm) }\end{array}$ & $\begin{array}{c}\mathrm{fl}: \mathrm{lfs} \\
\text { (fbn:m) }\end{array}$ & $\begin{array}{l}\text { fl:fbn } \\
\text { (fl:m) }\end{array}$ & $\begin{array}{c}\text { fr:lfs } \\
\text { (fr:m) }\end{array}$ & $\begin{array}{c}\text { la } \\
\left(\mathrm{cm}^{2}\right)\end{array}$ & $1: \mathrm{fn}$ & $\begin{array}{c}\text { LA:FW } \\
\left(\mathrm{cm}^{2} \cdot \mathrm{g}^{-1}\right) \\
\end{array}$ & $\begin{array}{l}\text { FW:bcsa } \\
\left(\mathrm{g}^{\circ} \mathrm{cm}^{-2}\right)\end{array}$ & $\begin{array}{l}f w \\
(g)\end{array}$ & $\begin{array}{l}\text { sw } \\
(\mathrm{g})\end{array}$ & fw:sw & $\mathrm{HS}$ \\
\hline $\mathrm{BB}$ & 0.40 & & & & & & & & & & & & & & & & & & \\
\hline $\mathrm{Bd}$ & 0.88 & 0.50 & & & ' & & & & & & & & & & & & & & \\
\hline Ad & 0.82 & 0.57 & 0.88 & & & & & & & & & & & & & & & & \\
\hline Bd:Ad & -0.78 & -0.28 & -0.76 & -0.83 & & & & & & & & & & & & & & & \\
\hline lfs & 0.07 & 0.19 & -0.10 & -0.14 & 0.25 & & & & & & & & & & & & & & \\
\hline bd & 0.85 & 0.48 & 0.91 & 0.76 & -0.70 & -0.11 & & & & & & & & & & & & & \\
\hline fbn:lfs & 0.07 & 0.25 & 0.05 & 0.28 & -0.10 & -0.17 & 0.07 & & & & & & & & & & & & \\
\hline fl:lfs & -0.77 & -0.52 & -0.88 & -0.77 & 0.64 & -0.02 & -0.77 & 0.24 & & & & & & & & & & & \\
\hline fl:fbn & 0.67 & -0.51 & -0.87 & -0.82 & 0.67 & -0.03 & -0.69 & 0.03 & 0.91 & & & & & & & & & & \\
\hline fr:lfs & -0.64 & -0.47 & -0.70 & -0.65 & 0.34 & -0.11 & -0.55 & 0.07 & 0.76 & 0.68 & & & & & & & & & \\
\hline la & 0.82 & -0.45 & -0.86 & 0.92 & -0.81 & -0.07 & 0.77 & 0.20 & -0.80 & -0.83 & -0.54 & & & & & & & & \\
\hline 1:fn & 0.64 & -0.46 & 0.63 & 0.56 & -0.45 & 0.50 & 0.53 & 0.80 & -0.60 & -0.69 & -0.60 & 0.61 & & & & & & & \\
\hline LA:FW & 0.52 & 0.53 & 0.47 & 0.72 & -0.41 & 0.20 & 0.27 & 0.25 & -0.48 & -0.57 & -0.56 & 0.60 & 0.55 & & & & & & \\
\hline FW:bcsa & -0.30 & -0.47 & -0.43 & -0.36 & 0.07 & -0.23 & -0.18 & 0.28 & 0.62 & 0.66 & 0.72 & -0.28 & -0.57 & -0.57 & & & & & \\
\hline fw & 0.79 & 0.36 & 0.88 & 0.70 & -0.76 & -0.02 & 0.83 & -0.14 & -0.87 & -0.86 & -0.56 & 0.78 & 0.72 & 0.31 & 0.41 & & & & \\
\hline sw & 0.81 & 0.56 & 0.78 & 0.78 & -0.80 & 0.13 & 0.78 & 0.04 & -0.79 & -0.74 & -0.51 & 0.85 & 0.70 & 0.44 & -0.23 & 0.84 & & & \\
\hline fw:sw & 0.05 & -0.11 & 0.59 & 0.33 & -0.44 & 0.17 & 0.50 & -0.35 & -0.57 & -0.58 & -0.35 & 0.38 & 0.42 & 0.14 & -0.44 & 0.72 & 0.27 & & \\
\hline HS & -0.64 & 0.29 & -0.51 & -0.33 & 0.55 & 0.30 & -0.56 & 0.30 & 0.39 & 0.28 & 0.29 & -0.41 & -0.22 & 0.04 & -0.07 & -0.61 & -0.44 & -0.61 & \\
\hline$P$ & -0.46 & -0.69 & -0.72 & -0.67 & 0.42 & 0.05 & -0.58 & -0.31 & 0.57 & 0.66 & 0.47 & -0.51 & -0.45 & -0.53 & 0.49 & -0.51 & -0.38 & -0.39 & -0.09 \\
\hline
\end{tabular}

Table3. Eigenvalues and propotion of the variability represented by the first four PCs in apricot germplasm grown in central Mexico.

\begin{tabular}{lccc}
\hline \hline PC & Eigenvalues & Proportion & Cumulative \\
\hline 1 & 11.06 & 0.55 & 0.55 \\
2 & 2.64 & 0.13 & 0.61 \\
3 & 2.00 & 0.10 & 0.79 \\
4 & 1.27 & 0.06 & 0.85 \\
\hline
\end{tabular}

Table 4. Correlations between original variables and the first four PCs representing apricot germplasm variability observed in central Mexico.

\begin{tabular}{lrrrr}
\hline \hline & \multicolumn{4}{c}{ PC } \\
\cline { 2 - 5 } Variables & \multicolumn{1}{c}{1} & \multicolumn{1}{c}{2} & \multicolumn{1}{c}{3} & \multicolumn{1}{c}{4} \\
\hline GH. & 0.89 & -0.19 & 0.02 & 0.22 \\
BB & 0.55 & 0.64 & 0.16 & 0.00 \\
Bd & 0.96 & -0.10 & 0.07 & -0.09 \\
Ad & 0.91 & 0.09 & 0.32 & -0.05 \\
Bd:Ad & -0.79 & 0.31 & -0.34 & -0.08 \\
Ifs & 0.01 & 0.48 & -0.47 & 0.67 \\
bd & 0.86 & -0.22 & 0.18 & 0.05 \\
fbn:lfs & 0.02 & -0.38 & 0.78 & -0.02 \\
fl:Ifs & -0.92 & 0.02 & 0.21 & 0.07 \\
fr:fbn & -0.91 & -0.08 & 0.10 & 0.18 \\
fr:Ifs & -0.74 & 0.20 & 0.29 & 0.19 \\
la & 0.90 & -0.04 & 0.24 & 0.11 \\
l:fn & 0.75 & 0.25 & 0.25 & 0.34 \\
LA:FW & 0.61 & 0.51 & 0.04 & 0.00 \\
FW:bcsa & -0.53 & -0.43 & 0.61 & 0.33 \\
fw & 0.90 & -0.27 & -0.11 & 0.05 \\
sw & 0.86 & -0.05 & 0.14 & 0.39 \\
fw:sw & 0.57 & -0.46 & -0.39 & -0.34 \\
HS & -0.46 & 0.80 & 0.70 & -0.18 \\
P & -0.67 & 0.38 & -0.16 & -0.42 \\
\hline
\end{tabular}

these trees generally tended to bloom very late in the season (with $\mathrm{BB}$ values of 4 and 5 in Table 1).

Thickness of fruiting spurs $(\mathrm{Bd})$ was closely associated with bd $(r=0.91)$, la $(r=0.86)$, fw $(r=0.88)$, and sw $(r=$ 0.78 ), but was generally less efficient, as it was correlated with a higher proportion of leaf tissue devoted to fruit production (r$=0.63,1: \mathrm{fn})$. The large buds were found entrees with more erect growth habit and thicker fruiting spurs with larger leaves, fruits, and seeds, which are generally less efficient. When $\mathrm{fl}$ : fbn was high, the number of flowers ( $r=0.91$, fl : ifs) and fruits $(r=0.68$, fr : Ifs) per meter of fruiting spurs was also high, as was $\mathrm{FW}$ :bcsa $(r=0.66)$ and $\mathrm{P}(r=0.66)$. However, the high $\mathrm{fl}: \mathrm{fbn}$ ratio was also associated with smaller leaves $(r=-0.83$, la $)$, fruits $(r=-0.86$, fw $)$, and seeds $(r=$ $-0.74, \mathrm{sw})$; a less erect $\mathrm{GH}(r-=-0.67)$; and pointed fruiting spurs $(r=-0.82$, Ad).

When all variables were integrated by principal components (PC), $85 \%$ of the variability observed was explained by the first four PC (Tables 3 and 4). PC1 represents mainly nine variables (GH, Bd, Ad, bd, LA, fw, sw, fr : ifs, and fl : fbn), while BB and HS were the most important traits integrated by PC2. The first six variables listed on PC1 integrate a compact group when PC1 and PC2 are plotted on a bidimensional plant (Fig. 1). Bud density (fbn : ifs) and production efficiency (FW: bcsa) become important for PC3, and lfs along with P are represented by PC4. Some traits, such as bd, that had a lower range of variability among phenotypes now become important.

Some other closely associated variables that constitute couples on the left side along the PC1 are P and FW : bcsa and fl : fbn and fr: Ifs. These variables reflect more closely the degree of adaptation to local conditions.

Tree group formation based on the 20 variables included in this study could provide an efficient selection tool for apricot breeding programs outside traditional growing regions. For example, 117-3, 118-3, and 1111-1 constitute a group when they are plotted on a tridimensional graph (Fig. 2). These seedlings were included under type $1 \mathrm{GH}$ and, even though productive, should be discarded, as they have smaller fruits and spurs with dry, pointed apices that resemble spines and demand more labor.

Natural and artificial selection includes some factors that have been important for adaptation to local conditions and here were associated with $\mathrm{fl}$ : fbn values that are higher than 0.2 and flower densities of at least $30 \mathrm{fl}$ : lfs (Table 1).

Trees with relatively large fruit, which constitute one of the main objectives of this breeding program, integrate a separate group toward the right side of the graph (Fig. 2). Hybridization between highly productive selections and those with larger fruit is expected to produce a wide range of phenotypes that will be the basis for selection.

Some of the associations reported here might not be as high 


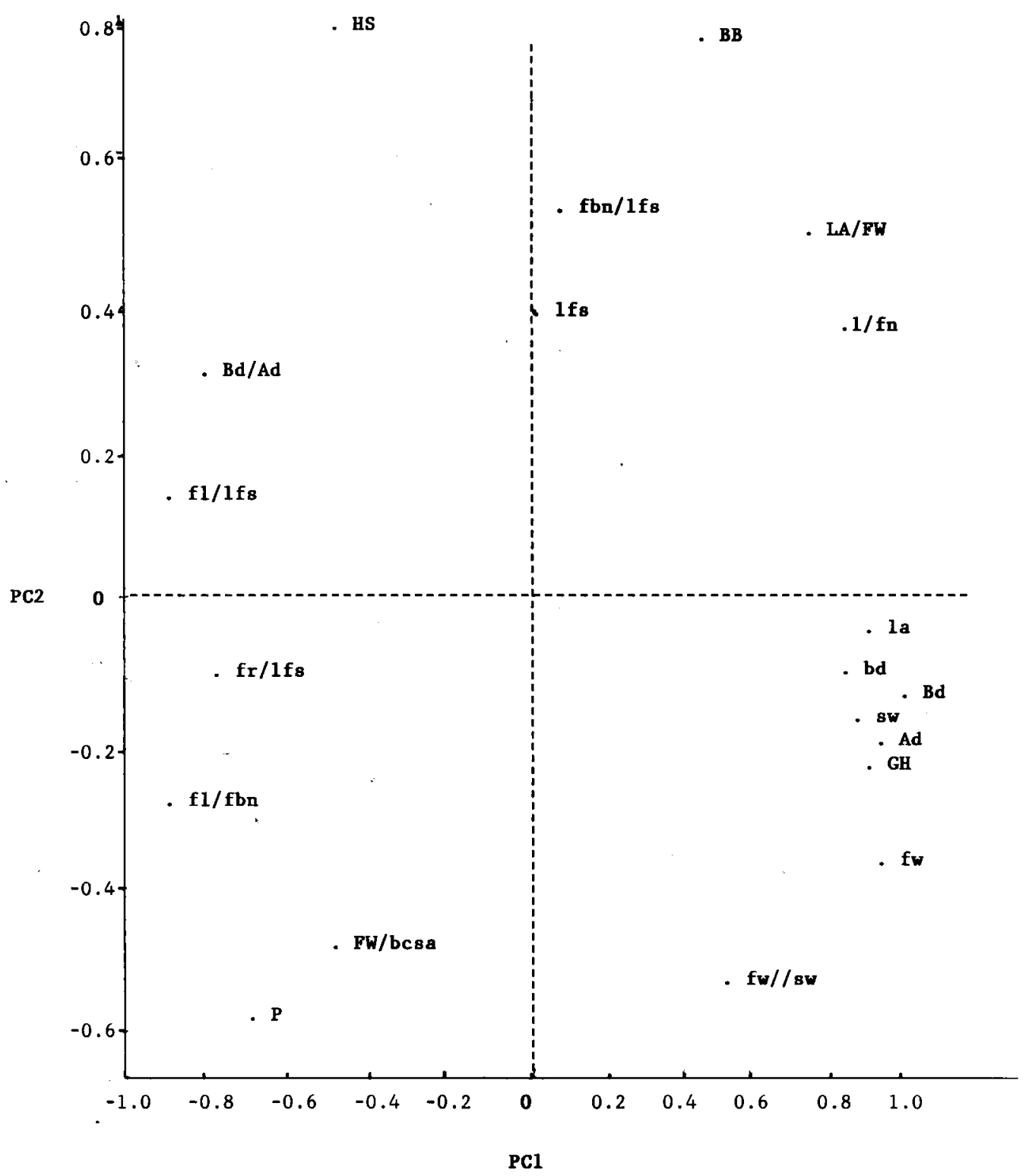

Fig. 1. Degree of association among variables of apricot germplasm as given by the relationship between PC1 and 2 for seedlings grown in Guanajuato, México.

during later stages of this or other breeding programs, when range of phenotypes is narrower. Nevertheless, intermittent characterization of apricot germplasm could detect some interesting correlations among some other traits, especially if they are related with several aspects of fruit quality, such as color, firmness, and flavor.

\section{Literature Cited}

Bailey, C.H. and L.F. Hough. 1975. Apricots, p. 367-383. In: J. Janick and J.N. Moore (eds.). Advances in fruit breeding. Purdue Univ. Press, West Lafayette, Ind.

Brayer, O. 1973. Fitogenetica aplicada, Ed. Limusa, Mexico.

Brooks, R.M. and H.P. Olmo. 1972. Register of new fruits and nut varieties. 2nd ed. Univ. of California Press, Berkeley, Calif.

Byrne, D.H. and T.G. Littleton. 1989. Characterization of isozyme variability in apricots. J. Amer. Soc. Hort. Sci. 114:674-678.

Caccamisi, D., G. Bergamini, M. Cavedoni, and F. Andreoli. 1987. Produzione e commercio delle albicoccho nel mondo. Frutticoltura 49:31-36.

Chang, L. S., A.F. Iezzoni, and J.A. Flore. 1987. Yield components in 'Montmorency' and 'Meteor' sour cherry. J. Amer. Soc. Hort. Sci. 112:247-251.

Couranjou, J. 1977. Variétés d'abricotier. Inst. National de Vulgarization pour les Fruits, Legumes et Champignons. Paris.

Crisci, J.V. and A. Lopez. 1983. Introducción a la teoría y practica de la taxonomía numerics. OEA-Programa Regional de Desarrollo Cientifico y Tecnología, Washington, D.C.

Crossa-Raynaud, P.H. 1969. Evaluating resistance to Monilinia laxa (Adherh. and Ruhl.) Honey in varieties and hybrids of apricots and almonds using mean growth rate of cankers on young branches as a criteria of susceptibility. J. Amer. Soc. Hort. Sci. 94:282-284.

Fideghelli, C. and F. Monastra. 1977. Monografia di cultivar de albicocco. MAF-Instituto Sperim. Frutticoltura, Rome.

Fideghelli, C., G. Della Strada, and F. Grassi. 1991. L'apporto del miglioramento genetico per il rinnovamento varietale del pesco. Frutticoltura 6:5-11.

Guerriero, R. and R. Watkins. 1984. Revised descriptor list for apricot (Prunus armeniaca L.). International Board for Plant Genetic Resources, EEC, Brussels.

Hilling, K.W. and A. Iezzoni. 1988. Multivariate analysis in a sour cherry germplasm collection. J. Amer. Soc. Hort. Sci. 113:928934. 


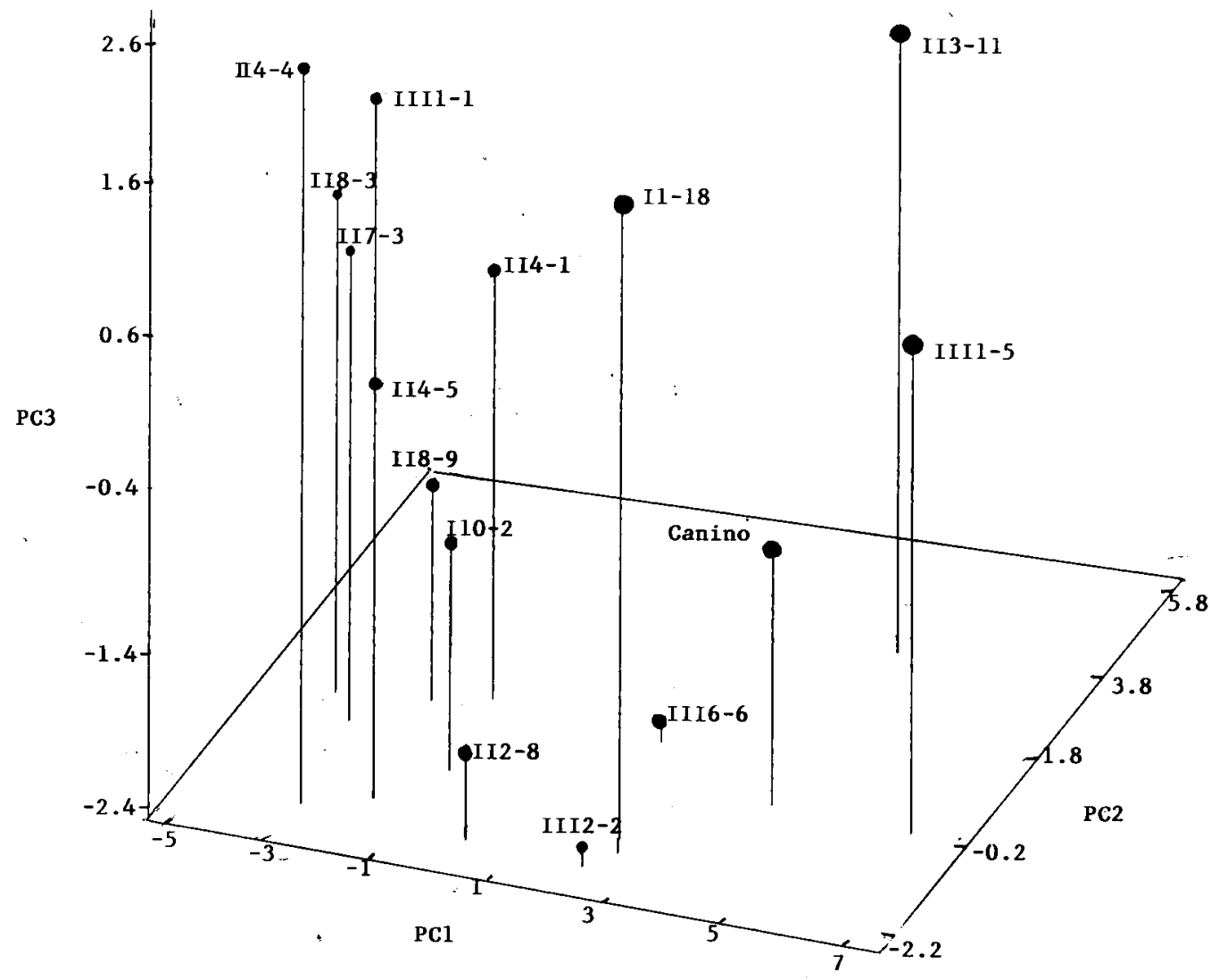

Fig. 2. Grouping of apricot tree genotypes grown in Guanajuato, México, as given by the relationship between PC 1, 2, and 3. Circle size reflects fruit weight.

Iezzoni, A.F. and M.P. Pritts. 1991. Application of principal component analysis to horticultural research. HortScience 26:334-338.

Kappel, F. 1990. Yield component analysis of 'Harrow Delight', 'Kieffer', and 'Harvest Queen' pear. J. Amer. Soc. Hort. Sci. 115:2529.

Lapins, K. O., A.J. Mann, and. F.W. Keane. 1957. Progeny analysis of some apricot crosses. Proc. Amer. Soc. Hort. Sci. 70: 125-130.

Martin, G.B. and M.N. Adams. 1987a. Landraces of Phaseolus vulgaris (Fabaceae) in northern Malawi I. Regional variation. Econ. Bet. 41:190-203.

Martin, G.B. and M.N. Adams. 1987b. Landraces of Phaseolous vulgaris (Fabaceae) in northern Malawi. H. Generation and maintenance of variability. Econ. Bet. 41:204-215.

Monastra, F., C. Fideghelli, G. Grassi, G. Della Strada, F. Penone, D. Proto., and V. Magliano. 1984. Monografia agronomic e tecnologica di cultivar da industria di albi- cocco, pesco e susino. Cassa per il Mezzogiomo, Rome.

Montez, S. 1989. Evaluacion de los efectos de domesticacion sobre el tomate (Physalis philadelphica Lam.) MS Thesis, Colegio de Postgraduados, Chapingo, Mexico.

Sansavini, S., V. Lunati, and C. Cacichi. 1987. L'apporto dells sperimentazione e dells tecnica allo sviluppo dells coltura dell'albicocco. Frutticoltura 49:37-46.

Scalabrelli, G. and G.A. Couvillon. 1986. The effect of temperature and bud type on rest competition and the GDH C requirement for budbreak in 'Redhaven' peach. J. Amer. Soc. Hort. Sci. 111:537540.

Scorza, R., L. Zailong, G.W. Lightner, and L.E. Gilreath. 1986. Dry matter distribution and responses to pruning within a population of standard, semidwarf, compact, and dwarf peach seedlings. J. Amer. Soc. Hort. Sci. 111:541-545.

Siefker, J.H. and J.F. Hancock. 1986. Yield component interactions in cultivars of the highbush blueberry. J. Amer. Soc. Hort. Sci. 111:606-608

Westwood, M.N. 1975. Temperature zone pomology. W.H. Freeman, San Francisco. 